\title{
Transe e desconstrução: a repetição nos corpos de Copacabana mon amour e A idade da terra ${ }^{1}$
}

\author{
Alexandre Wahrhaftig' \\ https://orcid.org/0000-0003-3994-2284 \\ I - Universidade de São Paulo. \\ São Paulo (SP). Brasil.
}

Resumo: Apesar das querelas entre seus diretores e dos quase dez anos que os separam, há muitas proximidades entre os filmes Copacabana mon amour (1970), de Rogério Sganzerla, e A idade da terra (1980), de Glauber Rocha. Dentre os vários elementos que imantam um filme ao outro, destaca-se a performance dos corpos em cenas marcadas por excessivas repetições tanto de gestos quanto de falas. O objetivo desse artigo é, através da análise comparativa, investigar como os dois filmes elaboram a repetição no sentido tanto de apreender o transe místico, elemento central para o filme de Sganzerla, quanto no sentido de desconstruir o próprio andamento do discurso fílmico, algo mais proeminente no filme de Glauber, questões fundamentais na alegoria de ambos.

Palavras-chave: repetição; transe; Glauber Rocha; Rogério Sganzerla; cinema brasileiro.

\footnotetext{
Abstract: Trance and deconstruction: repetition of bodily performance in Copacabana mon amour and $\boldsymbol{A}$ idade da terra - Despite the quarrels between their directors and the almost ten years that separate them, there are many close links between the films Copacabana mon amour (1970), by Rogério Sganzerla, and A idade da terra (1980), by Glauber Rocha. Among the various elements that magnetize one film towards the other, the performance of the bodies on stage marked by excessive repetitions of both gestures and 
speech stands out. The aim of this article is, through comparative analysis, to investigate how the two films elaborate repetition both in the sense of apprehending the mystical trance, a central element for Sganzerla's film, and in the sense of deconstructing the very progress of the filmic discourse, something more prominent in Glauber's film, fundamental issues for the allegory they construct.

Keywords: repetition; trance; Glauber Rocha; Rogério Sganzerla; Brazilian cinema.

\section{Introdução: Glauber Rocha e Rogério Sganzerla em comparação}

As trajetórias de Glauber Rocha e de Rogério Sganzerla, tanto fílmicas quanto extra-fílmicas, foram marcadas por pontos de atração e repulsão intensos. No terreno extra-fílmico, as duas personas encabeçaram uma rivalidade deflagrada na passagem da década de 1960 para 1970 entre o movimento do Cinema Novo e o movimento de um novo cinema emergente que ganharia a alcunha (à revelia de muitos de seus cineastas) de Cinema Marginal, rivalidade expressa principalmente na imprensa, em entrevistas, ou em cartas a colegas e amigos ${ }^{2}$.

No terreno propriamente fílmico, houve espaço para encontros mais frutíferos, em meio a divergências estéticas mais ou menos evidentes. Os dois cineastas sempre foram muito comprometidos com uma elaboração alegórica do Brasil e de seu subdesenvolvimento, afeitos a uma exploração formal singular e fragmentária distante da narratividade mais convencional ${ }^{3}$. Mesmo com diferenças fundamentais, as obras dos dois tocam-se em muitos pontos, nem que seja justamente como oposição ou ironia referencial — vide, por exemplo, o uso que Sganzerla faz em seus filmes de trilhas musicais emblemáticas da obra glauberiana.

2 Destaca-se, nesse sentido, a famigerada entrevista que Sganzerla concedeu com Helena Ignez para O Pasquim, em que se posiciona frontalmente contra o Cinema Novo e contra Glauber Rocha em particular, qualificando o último filme deste à época ( $O$ dragão da maldade contra o santo guerreiro) como "Iixo", "filme primário" que "agride pela burrice" (SGANZERLA, IGNEZ, 1970, p. 13). Da parte de Glauber Rocha, ele considerou Sganzerla um "oportunista", parte de uma geração que "decaiu pelo revisionismo", líder do cinema que ironicamente chamou de udigrudi, "uma dissidência golpista e arrependida do cinema novo" (ROCHA, 2004, p. 188; 365-366; 438). E, em carta a Michel Ciment, chegou ao ponto de chamar Sganzerla de "fascista" (ROCHA, 1997, p. 373).

3 As análises de Ismail Xavier presentes, principalmente, em Alegorias do subdesenvolvimento e em O cinema brasileiro moderno (XAVIER, 2004, 2012) colocam em mais de um momento Glauber e Sganzerla em comparação e são, nesse sentido, fundamentais para pensar a relação que as obras dos dois tecem entre si. 
A elaboração da figura da repetição pelos dois cineastas representa um ponto de contato fértil entre suas obras que merece um olhar atento. Os filmes Copacabana mon amour (1970) e A idade da terra (1980), separados por quase uma década, abusam de repetições internas (de gestos, falas, planos) de tal forma que são imantados um em direção ao outro, o que faz com que a presença de tal gesto formal (a repetição) se ilumine a partir da comparação.

Em termos metodológicos, o "fazer comparatista" ainda é muito pouco teorizado no meio de cinema em relação, por exemplo, à disciplina mais estabelecida da "literatura comparada", mas não menos presente nas atividades críticas, teóricas e curatoriais do meio, conforme explica Mariana Souto em sua tese (SOUTO, 2019, p. 37-44). A autora frisa ainda que a comparação não deve ser apenas um método, mas uma "perspectiva que influencia na formulação mesma das perguntas", uma "premissa sobre a qual se assenta o estudo", lembrando que as obras estão sempre em "relações de alteridade" umas com as outras (Idem, 2019, p. 40).

Sem nos filiarmos, pois, a um modelo de "fontes e influências", bastante em voga no início da literatura comparada, que visava conexões entre autores limitando-se ao que era "documentado e comprovável" (SOUTO, 2019, p. 39) e sem, também, aderirmos à problemática das origens de determinadas imagens, como sugere a taxonomia do crítico Phillipe Arnaud, que pensa a articulação entre as imagens de diferentes obras segundo as possibilidades de "citação", “empréstimo", "roubo", "reprise", "remake", "reminiscência", "motivos arquetípicos" ou "filiação" - termos todos que denotam uma preocupação com rastrear de onde as imagens vem (ARNAUD, 1996, p. 383) nosso trabalho de comparação, para usar as palavras do "comparatista" Ismail Xavier, parte da "escolha de uma categoria central a partir da qual é possível montar um eixo onde diferenças e semelhanças se cristalizam e permitem tornar visível a história", escolha que inclui uma dimensão de intuição crítica (XAVIER apud SOUTO, 2019, p. 43).

No nosso caso, foi a percepção do motivo da repetição nos dois filmes que orientou sua escolha como categoria central da comparação para, a partir dela, melhor compreender a singularidade de cada uma das obras na lida com determinados problemas estéticos e políticos, além de ressaltar a própria singularidade da repetição enquanto procedimento artístico. E ainda que façamos referência a documentos extra-fílmicos, o fundamental se desenvolve a partir das imagens e sons dos filmes de Glauber e Sganzerla. 


\section{Dois filmes distantes, dois filmes próximos}

De saída, notamos uma enorme distância entre os dois filmes quanto a seus processos de produção. Copacabana mon amour faz parte dos filmes da produtora Belair (fundada por Sganzerla com Helena Ignez e Júlio Bressane), conhecida por produzir, em apenas dois meses no ano de 1970, seis longasmetragens e um curta-metragem. Ou seja, trata-se de uma produção marcada pela urgência na realização e pelo seu caráter independente. A idade da terra, por sua vez, é um projeto de grandes proporções, gestado ao longo de anos, que Glauber tentou viabilizar inclusive internacionalmente ${ }^{4}$ até, enfim, lograr a realização com produção da Embrafilme. As filmagens ocorreram espaçadas em vários meses e por três regiões do Brasil (nas cidades de Salvador, Brasília e Rio de Janeiro). O filme, uma vez finalizado, foi exibido em festivais de cinema e em circuito comercial. Já Copacabana mon amour teve esparsas sessões entre 1970 e 1973, sendo lançado comercialmente somente em $1977^{5}$. Não encontramos indícios em texto de que Glauber teria visto Copacabana mon amour, mas Sganzerla certamente conheceu $A$ idade da terra, o qual inclusive defendeu em seu elogioso necrológio de Glauber, afirmando que o filme fora incompreendido no Brasil e no mundo, e destacando a "perfeição" de sua "tese ecumênica" (SGANZERLA, 2010b, p. 106, 108).

Curiosamente, a partir de distintos e aparentemente opostos esquemas de produção, nasceram duas visualidades próximas: ambos filmados em scope e com um apurado colorido (que em Copacabana mon amour se alterna com imagens em preto e branco) - semelhança que levou um crítico como Jairo Ferreira a falar que Glauber "cita sem ter visto" o filme de Sganzerla, o qual, injustamente, o crítico considera "péssimo" (FERREIRA, 2016, p. 182-3). Quanto à sonoridade, a edição de som e a mixagem da trilha musical também guardam semelhanças: ambos apresentam uma gama heterogênea de músicas, trabalhadas constantemente com entradas e saídas bruscas.

4 Em dossiê dedicado ao filme, a revista Contracampo apresenta uma série de documentos demonstrando a longa gestação e transformação do projeto de Glauber ao longo dos anos. Houve, conforme sintetiza Ruy Gardnier, até uma adaptação do projeto para o México em função dos contatos de Glauber com o presidente do Banco Cinematográfico do México; sem sucesso, Glauber teria ainda tentado produzir o filme nos Estados Unidos (GARDNIER, 2005).

5 As informações sobre as exibições de Copacabana mon amour estão na dissertação de mestrado de Anna Karinne Ballalai (2014, p. 30, 96-7). É preciso lembrar também que o filme possui múltiplas versões remontadas por Sganzerla ao longo das últimas décadas. Para nossas análises, guiamo-nos pela cópia restaurada de 2013, assim como o faz Ballalai (2014, p. 23). 

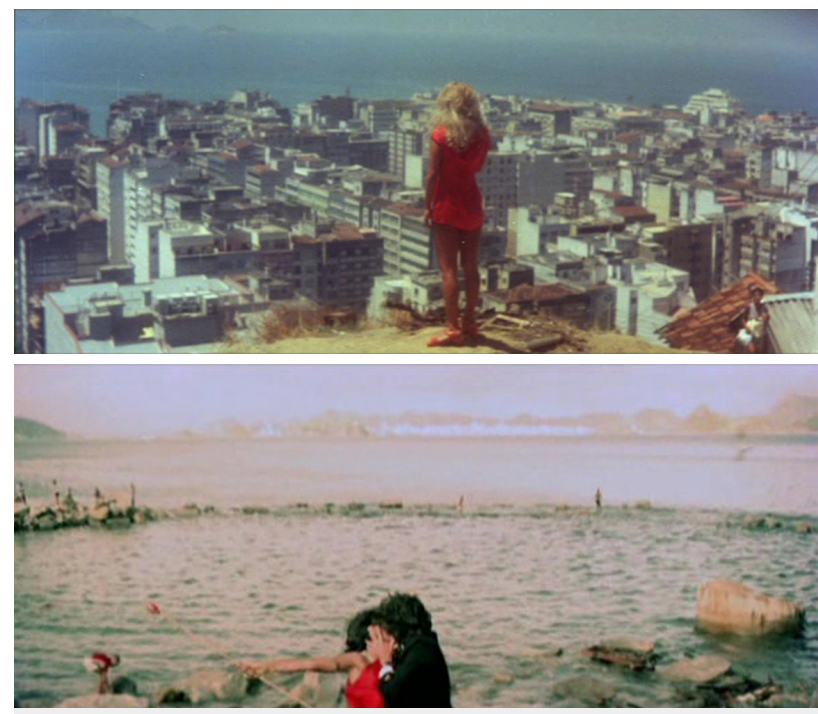

Figura 1. Copacabana mon amour e A idade da terra: imagens coloridas em scope

Outro ponto comum a que devemos dar especial atenção é a presença da religião nos filmes. Referências a umbanda e ao candomblé ${ }^{\text {são constantes }}$ em ambos, sendo que o filme de Glauber tem uma visada um tanto mais "ecumênica", ao mesmo tempo que explicitamente crística e evangélica. Mas mais do que simples referência, a religião é elemento estrutural, que atravessa os dois filmes do início ao fim, ainda que com sentidos distintos.

A idade da terra, grosso modo, é um painel alegórico pelo qual acompanhamos momentos da vida de quatro Cristos no Brasil (Antônio Pitanga, Geraldo del Rey, Jece Valadão e Tarcísio Meira) em contraponto ou em relação à presença no país do industrial imperialista Brahms (Maurício do Valle) ${ }^{7}$. Copacabana mon amour, também de pendor alegórico, mas aparentemente menos universalizante em suas ambições, mostra o cotidiano da personagem Sônia Silk (Helena Ignez) e de seu irmão Vidimar (Otoniel Serra), dividido

6 Há uma dificuldade, em diversas sequências, de precisar qual religião específica é apresentada pelos filmes. Estão presentes elementos tanto da umbanda quanto do candomblé, religiões que, apesar de intersecções, são distintas. Em artigo sobre etnologia no cinema brasileiro, por exemplo, Francisco Santiago Júnior fala do rito que aparece no início de Copacabana mon amour como indeterminado entre candomblé ou umbanda (SANTIAGO JÚNIOR, 2014, p. 418).

7 Segundo Ivana Bentes, "Trata-se de um filme que mal pode ser descrito ou contado, qualquer leitura parece 'fechar' demais todos os caminhos abertos" (BENTES, 1998, p. 151). Nas palavras de Glauber Rocha, por exemplo, A idade da terra seria justamente a "antítese da dramaturgia ocidental" (1985, p. 235), a "desintegração da sequência narrativa" (2004, p. 497). 
entre o morro onde moram e as ruas de classe média onde trabalham ela, como prostituta, e ele, como empregado doméstico do “Dr. Grilo" (Paulo Villaça). Uma diferença de escala geográfica e política se evidencia na comparação entre os filmes. No filme de Glauber, o destino do Brasil parece estar inteiro implicado nas ações das personagens (do Brasil e do mundo, já que a missão do industrial Brahms é "destruir a Terra" conforme enuncia no início), enquanto que, no de Sganzerla, o âmbito das ações pode parecer muito mais localizado (o personagem que faz as vezes de antagonista é um mesquinho patrão doméstico). Os próprios títulos das obras sugerem a diferença de escala em que se colocam: Glauber em uma escala planetária e geológica; Sganzerla em uma escala local, de um bairro do Rio de Janeiro.

Mas as coisas não são tão simples. Como bem nota Anna Karinne Ballalai, Copacabana mon amour tem momentos marcantes de ampliação geográfica, inclusive para o "âmbito planetário", como no discurso crítico proferido em off por Sônia Silk em que ela afirma ser preciso mudar a face do planeta. Ballalai encontra um ponto de ligação forte do filme de Sganzerla com A idade da terra na "dimensão planetária" que ambos assumem em sua crítica inspirada por Frantz Fanon (Cf BALLALAI, 2014, p. 135-6). Há também uma ambivalência no próprio título: Copacabana mon amour, ao mesmo tempo que atesta o localismo, o faz através da língua francesa e, mais do que isso, através da referência ao filme de Alain Resnais, Hiroshima mon amour (1959), em um procedimento paródico que entrelaça a imagem de Copacabana pós Al-5 à imagem do terror nuclear de Hiroshima.

Além das escalas espaciais, as escalas temporais também guardam agudos comentários políticos. À primeira vista, novamente uma oposição. Do lado de Glauber, um filme que aglutina diferentes épocas e escalas de acontecimentos; que narra tanto a criação do mundo e o nascimento de um Cristo, quanto um contemporâneo desfile de escola de samba e uma localizada entrevista sobre a política externa do governo militar. Mais do que isso, é um filme que aponta para o futuro, atravessado por um tom messiânico evangélico e profético, termos basilares nas análises de Ismail Xavier $(1981,1998)$ sobre a visão mítica de A idade da terra. Já do lado de Sganzerla, um filme aparentemente todo calcado no presente dos anos 1970, impregnado do cotidiano urbano da época com suas deambulações pelos morros e ruas, rituais de ebó, conversas (e jogos de poder) em apartamentos, tudo sem orientação teleológica ainda que haja alguma transformação ao final (Dr. Grilo é assassinado). 
A moldura de época, porém, é rompida tanto pela trilha sonora (que alterna gravações antigas de Noel Rosa com pontos de umbanda e canções de Gilberto Gil feitas para o filme), quanto pela ocasional voz do narrador sobre as imagens que, além de localizar o tempo do filme nas "proximidades da Idade da Pedra", explica que Sônia Silk teria vindo ao Brasil em 1635 em um navio negreiro. Tais informações e comentários adicionam um elemento novo à equação temporal do filme, reforçando o arcaísmo que permeia o presente e explicitando a origem colonial escravocrata da condição urbana contemporânea - um procedimento de sobreposição temporal típico do tropicalismo com suas justaposições paródicas do arcaico e do moderno ${ }^{8}$. Semelhante efeito encontramos em $A$ idade da terra, por exemplo, quando Brahms aponta para a obra do teatro de Brasília e para seus operários e diz: "Há 500 anos que meus escravos estão construindo essa pirâmide, que no futuro será meu túmulo". A referência à civilização egípcia antiga mediada pelos 500 anos do colonialismo indica, ao mesmo tempo, as ambições mítico-imperialistas globais de Brahms e seu posicionamento local na história nacional, colocando o presente como um palimpsesto de tempos no qual é possível relacionar o operário contemporâneo à escravidão passada.
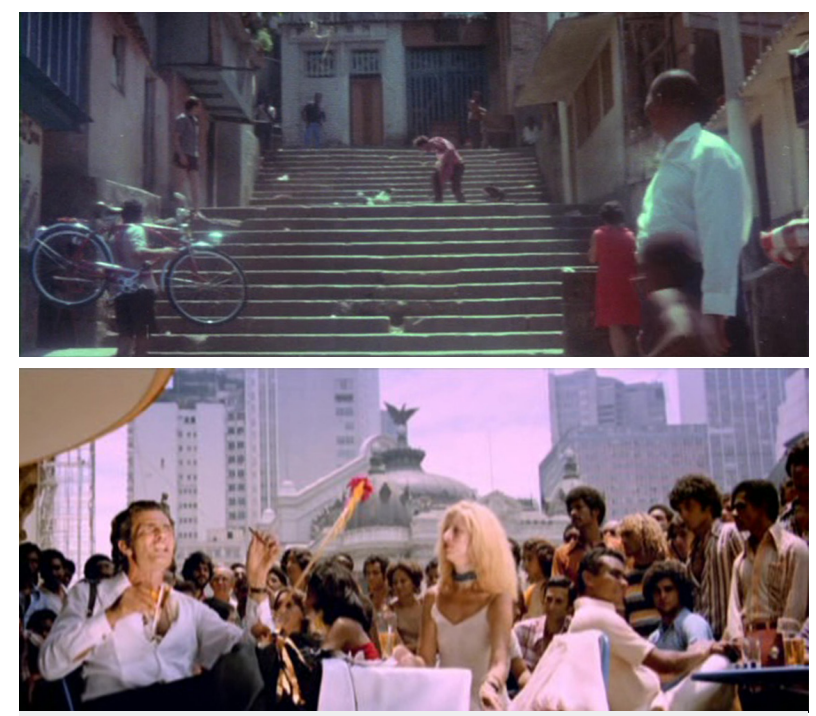

Figura 2. Copacabana mon amour e A idade da terra: espectadores em cena

8 A relação do tropicalismo com os cinemas de Glauber Rocha e de Rogério Sganzerla já foi bastante analisada por Ismail Xavier (2012). É interessante notarmos nomes de peso do tropicalismo na equipe de ambos os filmes: Gilberto Gil em Copacabana mon amour e Rogério Duarte em A idade da terra. 
Se as breves descrições até aqui feitas poderiam sugerir estarmos diante de filmes um tanto conceituais com suas elaborações histórico-políticas do tempo e do espaço, é preciso ressaltarmos que são, mais do que "cerebrais", filmes extremamente físicos, sensuais, pulsionais, eróticos, agonizantes. 0 grito, o canto, a nudez, a dança e a violência compõem a tônica dos corpos em cena. A performatividade esgarça a representação e faz emergir com força a fisicalidade dos atores e atrizes, tensionando a carga ficcional e conceitual da cena com a presença corpórea. Não à toa, os dois filmes, sensíveis à potência da performance de seus atores e atrizes, fazem coexistir e colidir in loco o jogo cênico dos corpos do elenco com os corpos de espectadores mais ou menos involuntários das filmagens.

\section{Corpos em transe}

É pelos corpos, justamente, que a maior parte das repetições em Copacabana mon amour emerge, o que caracteriza, em uma primeira leitura, as personagens com tiques e manias. Mais de uma vez, Sônia cospe cerveja na calçada. Mais de uma vez, Vidimar sai correndo, pulando, caindo e gritando. Mais de uma vez, o cafetão interpretado por Guará Rodrigues brinca com seu canivete. Tudo isso parece, a princípio, uma forma de caracterização de personagem por reiteração, algo comum na caracterização de personagens-tipo, caricaturais ou planos, personagens marcados por uma única ideia, reiterada constantemente (FORSTER, 1985, p. 67). No filme, isso contribui para a alegorização da obra, esvaziando a psicologia das personagens e marcando, cada uma delas, com uma função na economia global da alegoria: o funcionário apaixonado pelo patrão, no caso de Vidimar; a mulher que nega sua pobreza, reafirmando repetidas vezes que tem nojo de pobre, caso de Sônia Silk; o patrão que se coloca acima de todos, repetindo "quem manda aqui sou eu" etc ${ }^{9}$.

Em um outro nível, a repetição também incide sobre a temporalidade das sequências do filme: ao jogar os corpos em comportamentos cíclicos, que atravancam o desenvolvimento causal e linear das ações, o próprio filme é colocado sob esse movimento truncado. A sequência mais marcante em que isso ocorre é a do encontro de Sônia Silk com uma possível cliente, interpretada por Lillian Lemmertz. Esta convida Sônia para um programa

9 Anna Karinne Ballalai (2014, p. 115) e Estevão Garcia (2018, p. 129) lembram que a tipificação das personagens e seus reiterados bordões dialogam com o universo das histórias em quadrinhos, universo pelo qual Sganzerla nutria particular apreço. 
e Sônia responde, em desencontro à pergunta, repetidas vezes: “O pior é que eu tenho pavor da velhice, pavor da velhice!". Depois, a moça convida Sônia para irem à Argentina, "tudo pago", e novamente recebe a mesma resposta: “O pior é que eu tenho pavor da velhice, pavor da velhice!". O diálogo desencontrado se repete mais uma vez e, pouco depois, outras repetições se seguem; dentre elas, o incômodo bordão de Sônia: "Tenho nojo de pobre".

Esse emperrar constante do diálogo aponta para uma estranha força que atravessa as personagens e que parece baixar nelas como uma possessão. Copacabana mon amour é, afinal, profundamente marcado pela figura da possessão e por religiões de matriz afro-brasileira. Elementos da umbanda e do candomblé são constantes, tanto na trilha musical quanto na iconografia do filme - além de elementos ritualísticos, pode-se, por exemplo, ler as cores dos figurinos como referências a umbanda, vide a análise de Anna Karinne Ballalai sobre as relações da iconografia de Sônia Silk com a entidade da Pomba-Gira (BALLALAI, 2014, p. 90). E, além de cenas explicitamente ritualísticas, mais de uma vez ouviremos personagens falarem de possessão. Não à toa, no início do filme, Sônia aparece em um terreiro, com o babalorixá Joãozinho da Gomeia, e faz gestos de incorporação. Pouco depois, sua mãe grita que seus filhos estão possuídos pelo demônio (e o grita duas vezes, em repetição). Em seguida, Sônia aparece convulsionando e gritando para a mãe, repetidas vezes sem parar, que vai morrer naquele dia. De saída, o filme elabora uma espécie de chave de leitura em que "possessão" e repetição estão ligadas. E mesmo quando não há rituais e não há possessão literal, a repetição na performance do elenco guarda a energia do transe apresentada no início.

Assim, os bordões e as manias guardam um embrião de transe em cada repetição. E quando a situação realmente foge do verossímil da mera caracterização tipificante - como no diálogo entre Sônia Silk e a Turista Argentina o transe passa a ser ainda mais evidente, na medida em que produz uma descontinuidade no fluxo supostamente "contínuo" do real, descontinuidade que toma a forma de repetições. Conforme a repetição afeta a temporalidade dos corpos, colocando-os num eterno retornar sobre si, e conforme o filme não resume, acelera ou subtrai essa duração, ele se entrega também a tal temporalidade e todo ele é afetado pela energia transbordante do transe, via a duração das repetições, para além das evidentes convulsões dos corpos - ou melhor, talvez a própria repetição seja um signo de convulsão. O pesquisador Estevão Garcia chega a afirmar que o transe é uma 
palavra que pode classificar não só a interpretação do elenco, mas o próprio filme Copacabana mon amour, cuja fábula seria "conduzida por gestuais em convulsão" (GARCIA, 2018, p. 132), ao que acrescentaríamos, em repetição.

Convulsões, gestos expansivos, gritos, rodopios e, não menos marcantes, repetições atravessam os corpos de $A$ idade da terra de forma semelhante ao que ocorre no filme de Sganzerla. O retorno de determinadas falas nas bocas das personagens também compete para marcar uma redução de psicologia e, consequentemente, reforçar a alegoria crística e política do filme, mas, sem o clima de "cotidiano" da Copacabana de Sganzerla, a ideia de tipificação das personagens não se faz presente: os seres que vemos são Cristos do Terceiro Mundo e não tipos que se encontram pelas ruas da cidade.

O transe se mantém como possibilidade para compreender o jogo do elenco nesse filme em que há manifestações e rituais religiosos-populares em abundância, a ponto de quase todas as cenas se "contaminarem" com uma carga ritualística. O fenômeno da possessão, porém, não é explorado com tanto peso, o que faz com que o transe apareça mais como uma ideia geral do que como um núcleo temático-formal, ideia geral que se sustenta enquanto "transe" graças, em parte, ao histórico do termo na trajetória do cineasta, com destaque óbvio para Terra em transe (1967), filme em que a convulsividade se descola do âmbito religioso para se dobrar sobre os acontecimentos políticos e históricos representados.

Em $A$ idade da terra, o âmbito religioso é constantemente referido e aparece, enquanto manifestação popular, como contraponto central ao imperialismo da figura de Brahms. Para Ismail Xavier, há uma "atmosfera de redundância" nesse esquema em que as significações tornam-se óbvias (XAVIER, 1981, p. 72) e em que a armadura alegórica recai numa "generalidade excessiva" e quiçá conservadora ao relegar a salvação à figura de Cristo (XAVIER, 1998, p. 165; 177). A repetição nos corpos, contudo, pode propor uma outra leitura.

\section{A desconstrução}

Por mais que o fragmentado A idade da terra tenha um lado mais maniqueísta e utópico que o amoral Copacabana mon amour, a repetição, quando "baixa" nos corpos, extrapolando a ideia de transe e possessão, complexifica o discurso moral do filme. Dentro da economia de interpretação do elenco, ainda que uma certa convulsividade e exasperação atravesse todos os personagens, a repetição é um motivo que se destaca em uma figura específica, 
o Cristo Militar, cujas cenas podem ser consideradas verdadeiros tours de force de repetição.

Nelas, sem paralelos com o filme de Sganzerla, a repetição não é apenas mais um elemento da mise en scène e do jogo do elenco, mas, excessiva e agonizante, torna-se elemento fundamental da formalização cênica, produzindo uma sensação infernal de "condenação" por um eterno retornar da cena sobre si que em muito supera, sem juízo de valor, a sensação agonizante dada pelas repetições de Copacabana mon amour. E, não à toa, no primeiro desses tours de force, Tarcísio Meira gritará, repetidas vezes em um discurso apocalíptico sobre a decadência do país: "Nós estamos condenados!".

Esta longa cena de longas falas repetidas é constantemente invadida pela voz de Glauber, em off, exigindo que o elenco a refaça. Entre as repetidas tomadas que se sucedem, Tarcísio Meira aparece descansando fumando um cigarro ou pegando o paletó que jogara ao chão em tomada anterior. A câmera, além de alucinada em movimentos desvinculados da ação do elenco, alterna o diafragma escurecendo e clareando a imagem. Na trilha sonora, a música surge e desaparece intermitente e bruscamente. Dentre todos esses signos da desconstrução do aspecto "fechado" da ficção, ou seja, signos de atenção ao seu processo construtivo, a repetição é o que chama mais a atenção, pois embala toda a sequência em sua duração extenuante. Nas palavras de Francisco Teixeira, ela seria "o principal meio de pôr a linguagem fora dos eixos [...]; um meio de pô-la em relevo, não como abstração-representação, como intensidade, perturbadora emissão" (TEIXEIRA, 2003, p. 90).

Tanto Anna Karinne Ballalai quanto Pedro Guimarães e Sandro de Oliveira, debruçados sobre a atuação de Helena Ignez, apontam para a quebra que a repetição promove em relação ao naturalismo e ao desenrolar temporal, como um recurso que "promove a reflexividade, suspende a ilusão, denuncia a forma como o filme foi construído" (BALLALAI, 2014, p. 113) ou como um princípio que "revela a ruptura dos seus personagens com uma percepção do tempo diacrônico" (GUIMARÃES; OLIVEIRA, 2019, p. 102). Isso que notam é certamente mais forte em $A$ idade da terra, principalmente pelo excesso do número de vezes que Tarcísio Meira chega a repetir um mesmo trecho de fala, implodindo qualquer "ilusão" possível ou "tempo diacrônico".

Pelo excesso, a repetição aprisiona o filme e os personagens em um tempo asfixiante, condenados, como sob castigos infernais. Em Copacabana mon amour, estão aprisionados no cotidiano e em suas ideias fixas, repetindo-se 
constantemente de forma a indicar a invariabilidade do cotidiano e a invariabilidade de seus pensamentos, talvez bloqueados pelo sol de Copacabana que, conforme dizem no filme, não os deixa pensar: repetição alegórica como signo da estagnação de um pensamento oprimido pelo sol, o sol do subdesenvolvimento e da miséria. Em A idade da terra, o sinal de condenação é mais complexo e vai além da ideia fixa que aprisiona.

Pois, se a repetição revela e desconstrói um pouco do trabalho do filme, ela também, no nível da ficção, acaba por revelar fissuras na construção das identidades das personagens. Em uma outra sequência do Cristo Militar, agora com o enquadramento fixo, ele declama praticamente seis vezes um mesmo discurso, com algumas pequenas variações, associando as "conquistas da nação" (Independência, Proclamação da República, Abolição da Escravatura) ao povo, mas, ao mesmo tempo, defendendo o uso da violência para proteger o povo. Ismail Xavier, apesar de suas reservas ao filme, elogia tais repetições pela força irônica de sua "paródia do pomposo" (XAVIER, 1981, p. 72). Para ele, o Cristo Militar surge como o personagem mais interessante do filme, pois capaz de articular ironia e humor ao discurso do filme. Ele não cai na chave da repulsa que Brahms inspira e nem na seriedade dos discursos evangélicos dos outros Cristos. Sua ambivalência é patente: “como figura que 'sobra', ele intui sua vulnerabilidade, o que torna mais intenso seu teatro de celebração das conquistas dos ancestrais entendidas como construção da identidade nacional" (XAVIER, 1998, p. 170). É como se víssemos um personagem querendo que acreditem (ou querendo ele mesmo acreditar) naquilo que diz, apesar da evidente contradição do discurso, razão talvez pela qual ele o repita insistentemente (não mais o sol que não deixa pensar, mas a contradição que não se deixa resolver, contradição que explicita a associação de uma narrativa da nação à violência contra o povo). A repetição torna-se, assim, sinal de corrosão e vacilação tanto do discurso das personagens, quanto do próprio filme, matizando seu suposto esquematismo teleológico e dando outros sentidos ao aspecto "em transe" de suas manifestações.

O próprio comportamento da câmera e da montagem de A idade da terra acentua essa corrosão constante do discurso. Em diversos momentos a câmera praticamente "convulsiona", alternando freneticamente zoom e diafragma enquanto desenquadra e reenquadra os corpos vertical e horizontalmente, muitas vezes ao compasso de uma "montagem nuclear" que 
estilhaça a unidade da cena em repetidos vais e vens ${ }^{10}$. O dispositivo de Copacabana mon amour é quase oposto: os corpos em geral são vistos em planos-sequência com câmera na mão - a câmera ora permanece imóvel e distante, ora caminha ao redor do elenco em uma sutil coreografia -, em uma espécie de respeito ao tempo e à duração dos corpos em transe.

Assim, mesmo que à câmera e à montagem de Glauber se possa predicar sem dificuldades o termo "em transe", o efeito parece compor uma "linguagem do transe" mais de desconstrução do que de elaboração fílmica de um transe religioso. Já em Sganzerla, sem perder de vista certa opacidade do discurso (uma desconstrução ao seu modo), o dispositivo de sua "linguagem do transe" parece ter como preocupação justamente apreender o transe dos corpos.
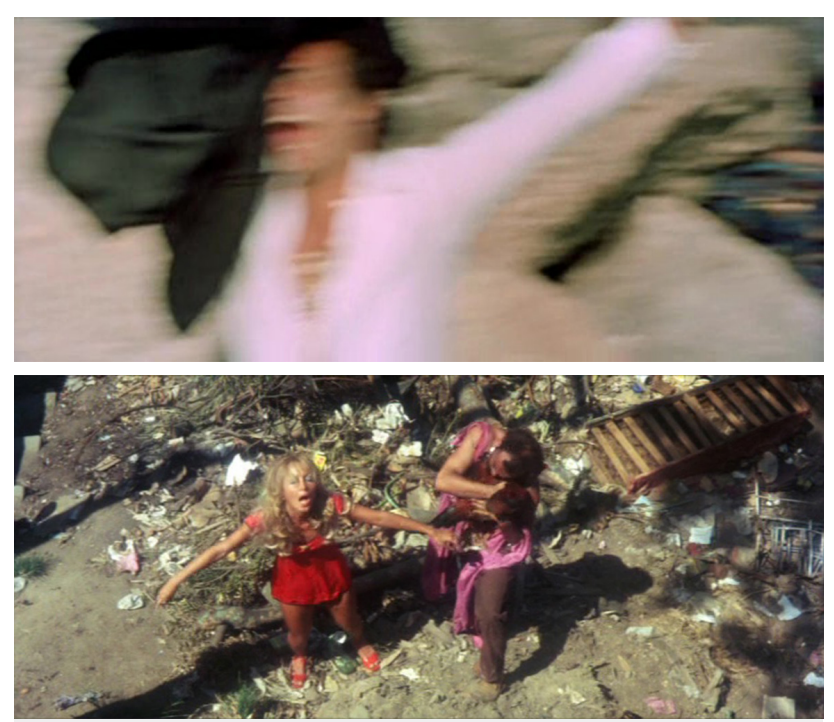

Figura 3. Copacabana mon amour e A idade da terra: "linguagem do transe"

É curioso notar como o problema da «linguagem do transe» é soprado aos ouvidos do jovem Sganzerla, em 1966, justamente pela boca do veterano Glauber Rocha em entrevista a respeito de seu filme Terra em transe, ainda

10 A expressão "montagem nuclear", da lavra de Glauber Rocha, é inspirada por concepções de montagem de Eisenstein, conforme demonstra Mateus Araújo Silva (2014, p. 214-5), pesquisador bastante implicado no "fazer comparatista" ao trabalhar com a obra de Glauber Rocha. 
em preparação. Glauber se indaga, ao ser perguntado por Sganzerla sobre o estilo de seu próximo filme "Qual é a linguagem do transe?" e continua:

O que me interessa no filme é o próprio transe - um ritmo e um clima que sejam transe. [...] Porque se eu não incorporar o transe à linguagem farei apenas o relato do transe e se o espectador não participar do transe, isto é, entrar no transe, o filme fracassa (SGANZERLA, 2010a, p 163-4).

O trecho acima é interessante não tanto por apresentar uma referência comprovável no passado para uma suposta influência ou origem do estilo de Sganzerla em Copacabana mon amour (leitura demasiado fechada), mas por explicitar o quanto os dois cineastas compartilham um compromisso ético-estético na incorporação do transe pela linguagem cinematográfica de seus filmes: para ambos não é possível apenas fazer o "relato do transe"11. Nesse sentido, em Sganzerla, a repetição é fundamental para carregar a duração dos corpos em transe à duração da experiência de assistir ao filme. A idade da terra, por sua vez, parece tão contaminado pela força convulsiva do transe, que passa a ser difícil apreendê-lo enquanto tal.

\section{Considerações finais}

Em ambos os filmes, de forte ímpeto alegórico, a repetição aparece entrelaçada, junto às performances expansivas e convulsivas dos corpos, com a crítica à agonizante condição social violenta do terceiro-mundo. O "sol que não deixa pensar", a possessão mística, o revirar do discurso, a ironia involuntária das "conquistas da nação", tudo parece indicar uma torção da representação diante da tentativa de abarcar a violenta experiência do subdesenvolvimento (tantas vezes explicitada verbalmente nos filmes). É assim que José Carlos Avellar, por exemplo, indica as pretensões de A idade da terra:

Levar o espectador a sentir com os olhos e ouvidos este sofrimento de quem se sente no meio do lixo do mundo, sem alicerces, vendo na loucura a única saída, vendo num discurso que critique a razão, e coloque no lugar dela só a emoção religiosa, a única arma eficiente para reagir (AVELLAR, 1981, p. 64).

11 Fernão Ramos, por exemplo, traz o transe como elemento que liga Sganzerla a Glauber em 0 bandido da luz vermelha, afirmando que o filme "evolui dentro de um estilo em 'transe', que não deixa de lembrar figuras glauberianas" (RAMOS, 2018, p. 181). 
Essa crítica da razão - defendida nos manifestos de Glauber, em "Estética da fome" e, mais ainda, em "Estética do sonho" (ver ROCHA, 2004) - liga-se intimamente ao fenômeno do transe, capaz de colocar os elementos do filme em uma rotação cíclica e conturbada em oposição à «razão conservadora» e ao "racionalismo colonizador" de que tanto fala Glauber Rocha (2004, p. 249250). No filme de Sganzerla, que também toma para si essa "loucura" de quem "se sente no meio do lixo" (há, pois, muito lixo em Copacabana mon amour, seja nas águas da baía da Guanabara, também representada por Glauber, seja nas lixeiras reviradas por Vidimar), a emoção religiosa não é a "única arma eficiente" de resistência. Ela é ambígua: é tanto sintoma quanto trampolim para a violência que leva à morte do Dr. Grilo, mas o assassinato é físico e não fruto de um "feitiço", como destaca Estevão Garcia (2018, p. 155-6) ${ }^{12}$.

O transe é esmiuçado com mais complexidade no filme de Sganzerla, enquanto que $A$ idade da terra, ainda que aluda às convulsões do transe pelos movimentos de câmera, zoom, montagem estilhaçada etc, sugere mais os impasses do processo de feitura da obra, do trabalho do pensamento, do filme e dos corpos. Ismail Xavier é inclusive bastante reticente quanto ao transe no filme, afirmando que ele é apenas esboçado, sem ressonân-

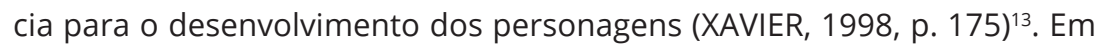
Copacabana mon amour, o transe é o que coloca todos os personagens em movimento, em atrito, em relação, sendo, portanto, central à unidade fragmentária da ficção e ao ritmo repetitivo que lhe imprime.

Na medida em que intensifica a força do transe ou tensiona a linguagem e narrativa cinematográfica, a repetição é elemento que aproxima os dois filmes, embalando-os com um ritmo infernal particular, na chave da condenação e da falta de saída, ainda que com um acento distinto em cada um (como em uma balança entre o transe e a desconstrução). Dada a semelhança incontornável dessa cadência de repetições em ambos, é interessante considerar também a distância de quase uma década entre eles e, mais do que isso, a proximidade da Copacabana de Sganzerla ao Al-5 e a proximidade da Terra de Glauber à abertura democrática, o que nos leva a uma hipótese de mão dupla.

Por um lado, os impasses e as convulsões das repetições extenuantes de Glauber acentuam o quanto o momento político de abertura não parece

12 Para uma análise da relação do filme de Sganzerla com os manifestos de Glauber, bem como a intersecção dos autores com o pensamento de Fanon, ver tese de Estevão Garcia (2018, p. 147-157).

13 Ainda que se possa contra-argumentar que a própria ideia de "desenvolvimento de personagem" colide com o projeto estético fragmentado e não narrativo de A idade da terra. 
representar a libertação almejada das violências e misérias do subdesenvolvimento e o quanto o período segue carregando a agonia dos tempos mais brutais da ditadura, uma agonia que o Cinema Marginal soube captar de forma bastante singular — vide as análises de Fernão Ramos (1987), por exemplo, que cita Walter Benjamin ao pensar nesse cinema como um estilo violento à altura da violência histórica (p. 142). O clima de condenação e agonia próprio de filmes marginais do período 1968-1973 permanece vivo em $A$ idade da terra, cuja ambígua vibração repetitiva de algumas sequências tanto grifa essa sensação quanto propõe uma desconstrução sensorial (quiçá utópica enquanto via de resistência). Por outro lado, pode-se aventar, retrospectivamente, que, ainda que a asfixiante conjuntura pós-Al-5 informe a estética do Cinema Marginal, aí incluído Copacabana mon amour, é a condição mais estrutural de país subdesenvolvido, de um passado colonial e escravocrata, que torna a agonia representada pelo transe de Copacabana tão disseminável pela década adiante, tão incorporável ao período de abertura democrática, conferindo um sabor amargo às mais diferentes conjunturas de nossa história.

Alexandre Wahrhaftig é doutorando no Programa de Pós-Graduação em Meios e Processos Audiovisuais da ECA-USP. No mestrado desenvolveu pesquisa sobre Abbas Kiarostami e atualmente estuda o motivo da repetição no cinema brasileiro moderno, com pesquisa financiada pela Fapesp. É também montador, diretor e fotógrafo.

lecowar@gmail.com

\section{Referências}

ARAÚJO SILVA, M. Eisenstein e Glauber Rocha: notas para um reexame de paternidade. In: MENDES, Adilson (org.). Eisenstein/Brasil/2014, p. 197-215. Rio de Janeiro: Azougue, 2014.

ARNAUD, P. “Répons (in)volontaires: insularismes cinématographiques". In: Pour un cinéma comparé: influences et répétitions. Paris: Cinémathèque française, 1996.

AVELLAR, J. C. O sentimento do nada. Filme Cultura, n. 38/39, p. 63-64, 1981.

BALLALAI, A. K. M. O ator em ato: a dialética ator/personagem em Copacabana mon amour. 2014. Dissertação de mestrado - UERJ, Rio de Janeiro, 2014.

BENTES, I. Romantismo, messianismo e marxismo no cinema de Glauber. Cinemais, n. 13, p. 137-152, 1998. 
FERREIRA, J. Cinema de invenção. Rio de Janeiro: Beco do Azougue, 2016.

FORSTER, E. M. Aspects of the novel. Londres: Harcourt, 1985.

GARCIA, E. P. Belair e Cine Subterráneo: o cinema moderno pós-1968 no Brasil e na Argentina. Tese em Mídia e Processos Audiovisuais. Escola de Comunicações e Artes, Universidade de São Paulo (ECA-USP), São Paulo, 2018.

GARDNIER, R. Dossiê Idade da Terra: apresentação. Contracampo - Revista de Cinema, n. 74, 2005. Disponível em: <http://www.contracampo.com.br/74/idadedaterradossieintro. htm>. Acesso em: 26 abr. 2018.

GUIMARÃES, P.; OLIVEIRA, S. Helena Ignez: actrice expérimentale. Trad. Cristophe Lecarpentier. Estrasburgo: Université de Strasbourg, 2018.

RAMOS, F P. Cinema Marginal (1968-1973): a representação em seu limite. São Paulo: Brasiliense, 1987.

. Cinema Novo/Cinema Marginal, entre curtição e exasperação. In: RAMOS, F. P.; SCHVARZMAN, S. (Orgs.). Nova história do cinema brasileiro, v. 2, p. 116-201. São Paulo: Edições Sesc, 2018.

ROCHA, G. Cartas ao mundo. São Paulo: Companhia das Letras, 1997.

Revolução do Cinema Novo. São Paulo: Cosac Naify, 2004.

Roteiros do terceyro mundo. Rio de Janeiro: Alhambra/Embrafilme, 1985.

SANTIAGO JÚNIOR, F. C. F. ...E a etnologia fez os cineastas sonharem: olhar etnológico e alteridade no cinema brasileiro entre 1970 e 1980. Boletim do Museu Paraense Emílio Goeldi. Ciências Humanas, v. 9, n. 2, p. 417-422, 2014.

SGANZERLA, R.; IGNEZ, H. Helena - a mulher de todos - e seu homem. O Pasquim, p. $11-15,1970$.

Edifício Rogério - Textos Críticos 1. Florianópolis: Ed. da UFSC, 2010a.

Edifício Rogério - Textos Críticos 2. Florianópolis: Ed. da UFSC, $2010 \mathrm{~b}$.

SOUTO, M. Infiltrados e invasores: uma perspectiva comparada sobre relações de classe no cinema brasileiro. Salvador: EDUFBA, 2019.

TEIXEIRA, F. E. 0 terceiro olho: ensaios de cinema e vídeo (Mário Peixoto, Glauber Rocha e Júlio Bressane). São Paulo: Perspectiva/Fapesp, 2003.

XAVIER, I. Alegorias do subdesenvolvimento: cinema novo, tropicalismo, cinema marginal. São Paulo: Cosac Naify, 2012.

O cinema brasileiro moderno. São Paulo: Paz e Terra, 2004. 
. Evangelho, terceiro mundo e as irradiações do planalto. Filme Cultura, n. 38/39, p. 69-73, 1981.

. A idade da terra e sua visão mítica da decadência. Cinemais, n. 13, p. 153-184, 1998.

Artigo recebido em 18/02/2020 e aprovado em 08/08/2020. 